but this is not what they have done: they merely show the two datasets are consistent with each other and, even so, there remain a few discrepancies. The authors also make the exciting suggestion that the solid inner core of the Earth is anisotropic, with axis of symmetry along the rotation axis of the Earth.

A. Morelli and A.M. Dziewonski ( $\mathrm{Na}$ ture in the press) have now mapped the surface of the fluid core using seismic waves that either travel through, or have been reflected from, the liquid core. This clever experiment evades the trap of mapping shallow structure onto the core surface. Reflected waves will arrive early if the core surface is shallow (if there is a bump on the core-mantle boundary) because it has less far to travel. A wave travelling through the same bump to the opposite side of the world will arrive late because waves travel slower in the core than the mantle. The effect of a bump on the core surface is therefore opposite for the two waves, but the effect of heterogeneity in the mantle should be the same. Good agreement is found between maps of the core-mantle boundary based on the two distinct datasets; it is unlikely to be caused by mantle heterogeneity and much more likely to result from true core topography.

Also, J. Bloxham and myself (Nature 317, 777-781; 1985) have mapped the magnetic field at the core surface for the past 265 years; we found permanent sites of stationary magnetic flux and other sites of persistent change in the magnetic field with time, as if the solid overlying mantle were controlling the field. This idea was suggested long ago by Raymond Hide but the theory could not be tested without information on the magnetic field and lower-mantle heterogeneity. We (Bloxham, J. \& Gubbins, D. Nature in the press) have now found that these magnetic field sites are related to the mantle temperature measured by seismic velocity, and possibly also to the core-surface topography.

Other approaches are being used to address the same questions. For example, small changes in the rotation of the Earth, now measured very accurately by very long baseline interferometry, provide other stringent limits on the lateral heterogeneity of the Earth (Gwinn, C.R. et al. J. geophys. Res. 91, 4755-4765; 1986). Again, if the mantle controls the magnetic field then the same field patterns should be seen in the palaeomagnetic record for many millions of years. It is too early yet to predict another revolution in the Earth sciences, but the new results allow the hope that several different observations will be brought into line with a theory for whole-Earth convection.

David Gubbins is in the Department of Earth Sciences, University of Cambridge, Bullard Laboratories, Cambridge CB2 1TT, UK.

\title{
Soft-hearted saurians in museum stores
}

The old adage, that many fossil discoveries are made in the museum basement, is confirmed by a recent study of ichthyosaurs, extinct marine reptiles like dolphins in form and habits, which highlights the often forgotten scientific importance of fossils in provincial museums'. Leicestershire Museums have a collection of ichthyosaurs from Lower Liassic bituminous shales in the nineteenth-century quarries of the Barrowupon-Soar district of Leicestershire. Their recent cleaning for display shows areas of exceptionally preserved soft parts such as skin, tendon and muscle or connective tissue. These areas, normally lost by decomposition before fossilization, are here preserved as very finely detailed mineral casts, masses of the bacteria and fungi which first decomposed the original tissue and then were killed and preserved by their own

\section{IMAGE UNAVAILABLE FOR COPYRIGHT REASONS}

waste products, mainly the minerals calcium phosphate or apatite. The top figure shows a complete ichthyosaur skeleton, 2.54 metres long, with patches of soft tissue preserved around the neck, forelimbs and base of the tail.

These ichthyosaurs from Barrow-upon-Soar provide important new evidence for the anatomy of the soft parts of these reptiles, complementing the more famous specimens from the Upper Lias of Holzmaden in Germany ${ }^{2}$. The soft tissues around the central bony skeleton of the forelimb show that the 'paddles' acted as hydrofoils, and have been used as evidence towards Jürgen Riess's radical reinterpretation of swimming in at least some ichthyosaurs: that they 'flew' underwater with their forelimbs like penguins, using the tail only for steering ${ }^{1,3}$. It remains to be seen whether the Barrow-upon-Soar specimens can be used as evidence for some other model of swimming. But even if we continue to accept that the large tail fin of many ichthyosaurs was the main propulsive organ, this analysis reminds us that ichthyosaurs, like many other marine animals, had at least two 'gears': slow swimming by moving the forelimbs; and fast swimming with the tail fin. These fossils, clearly important, are now unobtainable. The source quarries have long been closed. Even if the quarries were open today, modern mechanical methods of excavation would cause the loss of many fossils that would have been recovered during the smallscale hand digging previously customary - the bottom figure shows the hand-worked Barrow-upon-Soar lime pits. The quarries at Holzmaden continue to produce their fine fossils only because the heritage law forbids mechanical excavation of the fossilbearing strata, which are therefore dug by hand ${ }^{5,6}$. So, in the absence of open quarries, the palaeontologist must excavate in the museum cellar. Michael Taylor

1. Martin, J., Frey, E. \& Riess, J. Trans. Leicester Lit. Phil. Soc. 80, 58-72 (1986).

2. McGowan, C. Palaeontographica A 166, 93-135 (1979).

3. Riess, J. Palaeontographica A192, $93-155$ (1986).

4. Wade, M. Lethaia 17, $99-113$ (1984).

5. Keller, T. Geol Curator 4, 193 $-198(1985)$.

6. Wild, R. Geol. Curator 4, 275-280 (1986).
Michael Taylor was at the Area Museum Council for the South West, based at the City of Bristol Museum and Art Gallery, Bristol BS8 IRL, and has just moved to become Assistant Keeper (Earth Sciences), Leicestershire Museums, Leicester LEI 6TD, UK. 